aware of it but it seems to have been noticed first by Christiaan Huygens in Holland, who was twelve years older than Isaac Newton.

Returning to Newton's statement about 'force', the unknown influence that causes falling can be judged only by the effects that we say it produces. One effect is 'weight'. A balance shows us that the influence of the earth on two kilograms is just twice as great as its influence on one kilogram. Another effect of the influence is the gain in motion of an object that is free to fall. We might therefore study the falling motion of objects having masses of one kilogram and of two kilograms. We would watch for a gain that is doubled in the case of two kilograms, arguing that when the influence becomes doubled the effect chosen to measure it should become doubled too.

We have chosen objects heavy enough to make air friction negligible. Falling is rapid, but we can take a 'flash photograph', using perhaps ten flashes a second as a white ball falls in a darkened room before a stationary camera film. If the mass is one kilogram the distances the ball falls in successive tenths of a second are equal in metres to about $0.05,0.15,0.25,0.35$, 0.45 , and so on. The increasing speed shows that the influence of the earth causes a gain in velocity of about one metre a second in each tenth of a second.

When we do this again using a two kilogram ball, we look for a doubled effect. We may be surprised to find that the distances travelled are just the same as before. This need not worry us. To see a doubled effect we should look not at the gain in velocity but at the gain in momentum. To find momentum gain we multiply the gain in velocity by the mass of the moving object, one kilogram or two kilograms. Then clearly, the gains of the two kilogram ball are twice as great as the gains of the one kilogram ball. This shows that we should pick on the gains in momentum in order to measure the influence (the 'force'), just as Newton said. We might guess that he used the 'doubling' argument, just as we have done.

The foregoing account offers sutdents a means of demonstrating for themselves the meaning of 'momentum' and 'force'. If it were adopted as a teaching method in schools and universities I think that many students would understand dynamics better than they do now.

From a Stout Centre seminar on 6 June 1990.

\title{
Father rite/right/write : lesbians, the media and the child sexual abuse controversy.
}

\section{CHRIS ATMORE}

\section{$A P h D$ scholar and tutor in the Sociology Department of Victoria University of Wellington}

The paper was taken from my $\mathrm{Ph} . \mathrm{D}$ work in progress on print media constructions of lesbians in Aotearoa, from 1980 onwards. A post-structuralist reading was combined with lesbian feminist analysis in order to draw out the connections between the three homonyms: rite, right and write, and constructions of lesbians as they appear in dominant media discourses on child sexual abuse. I focussed particularly on two media topics: the use of child sexual abuse statistics in the 1988 Telethon campaign, and the Spence case, as constructed by North and

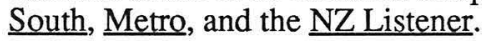

A number of typifications were present in the various media accounts, which I divided into dualisms and maskings. For example, what the Telethon and Spence accounts presented as a general wrong was the failure of researchers and child sexual abuse workers to operate within a specific scientific paradigm. Concepts like 'science', 'the facts', 'objectivity' and 'neutrality' were valued positively, and counterposed to their negatively valued opposities like 'subjectivity' and 'involvement'. The negative terms were associated with lesbian child sexual abuse workers. The location and unavoidable subjectivity of everyone in the field was denied, with lesbian feminism being presented as a conspiracy. 
Similarly, the dominant media accounts presented a politics of child sexual abuse where normal men and families were contrasted to monstrous abusers and their unnatural families. Sexual abuse was rare, sex was opposed to violence and protectors could not also be predators. In contrast the radical feminist view of violence against women and children collapses many of these dualisms. In opposing this the dominant media discourses used typologies which operated within a binary framework of male-female complementarity. Dualisms were constructed in terms of the reconcilable opposities, men and women, so that incompatibles were rejected. This forced a number of equally untenable accommodations of lesbians. I examined two major themes in the accounts: the lesbian as man-hater and the lesbian as predator. Both were an outcome of the interconnection of the various dualistic typologies and maskings. For example, chains of signification linked words like 'moderates', 'liberal feminists' and 'man lovers' which carried a positive association. These were counterposed to 'lesbian feminists', 'extremists' and 'man-haters'.

I concluded that the targeting of lesbians was not merely a misplaced form of scapegoating. Father right (power over, authority protected by law and custom, incest going largely unpunished); father rite (incest is common and cements male-dominant culture); and father write (the media accounts, accepted ways of doing research, and phallogogentric language) are interconnected. All are underwritten by compulsory heterosexuality, the man-woman dynamic as the 'natural' base. Definitions of abuse, of prevalence and a whole way of viewing the world are at stake in these conflicts. My reading of the accounts suggests that the targeting of lesbians as particularly biased, like the inherent contradictions and maskings of power in the media dualisms, ironically opens the way to a critique of all knowledge as situated, and therefore to challenges to the three forms of father 'rite'.

From a Stout Centre seminar on 13 June 1990.

\section{J D. Stout Fellow for 1991}

The 1991 John David Stout Fellow is Colin James, a political analysist and journalist who is perhaps best known for his book The Quiet Revolution (Allen and Unwin 1988). He intends to use the fellowship to write a book reviewing the changes in public policy in the 1980s and the context in which they were made: the intellectual, strategic and economic and other changes outside New Zealand which had an impact on New Zealand; and the changes within New Zealand in society, race relations, the economic structure and the attitudes of those in power in politics, the bureaucracy, business, unions and other spheres.

\section{NOTICES}

National Archives, Department of Internal Affairs, have advised that due to preparations for the move to their new Wellington Headquarters, Archives House, the following reductions to their Wellington services will be in force at both Atlas House and the Air New Zealand Building from 8 September 1990. All written and phoned reference enquiries are suspended from 1 December 1990.

Reading Room opening hours remain 9 a.m. - 5 p.m.

Production will cease at 12.30 p.m.

Reference services will cease at 1 p.m.

Supervised reading of pre-ordered materials till 5 p.m.

Further reductions to the Reading Room services will become necessary when the move takes place during 1991, at times to be advised. 